\title{
Correction to: ThalPred: a web-based prediction tool for discriminating thalassemia trait and iron deficiency anemia
}

\author{
V. Laengsri ${ }^{1,2}$, W. Shoombuatong ${ }^{3}$, W. Adirojananon ${ }^{2}$, C. Nantasenamat ${ }^{3}$, V. Prachayasittikul ${ }^{4}$ and P. Nuchnoi ${ }^{1,2^{*}}$
}

\section{Correction to: BMC Med Inform Decis Mak (2019) 19:212 \\ https://doi.org/10.1186/s12911-019-0929-2}

Following publication of the original article [1], the authors reported an error in one of the authors' names. In this Correction the incorrect and correct author name are shown. The original publication of this article has been corrected.

Originally the author name was published as:

- C. Nantasenamart

The correct author name is:

- C. Nantasenamat

\section{Author details}

${ }^{1}$ Center for Research and Innovation, Faculty of Medical Technology, Mahidol University, Bangkok, Thailand. ${ }^{2}$ Department of Clinical Microscopy, Faculty of Medical Technology, Mahidol University, Bangkok, Thailand. ${ }^{3}$ Center of Data Mining and Medical Informatics, Faculty of Medical Technology, Mahidol University, Bangkok, Thailand. ${ }^{4}$ Department of Clinical Microbiology and Applied Technology, Faculty of Medical Technology, Mahidol University, Bangkok, Thailand.

Published online: 19 November 2019

\section{Reference}

1. Laengsri $\mathrm{V}$, et al. ThalPred: a web-based prediction tool for discriminating thalassemia trait and iron deficiency anemia. BMC Med Inform Decis Mak. 2019;19:212. https://doi.org/10.1186/s12911-019-0929-2.

\footnotetext{
* Correspondence: pornlada.nuc@mahidol.ac.th

The original article can be found online at https://doi.org/10.1186/s12911019-0929-2

${ }^{1}$ Center for Research and Innovation, Faculty of Medical Technology, Mahidol University, Bangkok, Thailand

${ }^{2}$ Department of Clinical Microscopy, Faculty of Medical Technology, Mahidol

University, Bangkok, Thailand

Full list of author information is available at the end of the article
}

(c) The Author(s). 2019 Open Access This article is distributed under the terms of the Creative Commons Attribution 4.0 International License (http://creativecommons.org/licenses/by/4.0/), which permits unrestricted use, distribution, and reproduction in any medium, provided you give appropriate credit to the original author(s) and the source, provide a link to the Creative Commons license, and indicate if changes were made. The Creative Commons Public Domain Dedication waiver (http://creativecommons.org/publicdomain/zero/1.0/) applies to the data made available in this article, unless otherwise stated. 